\title{
Improving the accuracy and utility of harmful algal bloom forecasting systems
}

\author{
Donald M. Anderson, Bruce A. Keafer, Dennis J. McGillicuddy, Jr., Andrew R. \\ Solow, and Judith L. Kleindinst \\ Woods Hole Oceanographic Institution, Woods Hole, MA 02543 USA
}

\begin{abstract}
One of the goals of harmful algal bloom (HAB) research has been to develop predictive capabilities for blooms. Major steps have been made towards this goal, including the development of physical-biological models of HAB species that simulate bloom dynamics in specific regions. In the Gulf of Maine region of the northeastern U.S., models have been developed that have considerable skill in simulating blooms of Alexandrium fundyense, the causative organism for paralytic shellfish poisoning (PSP) outbreaks in the region. This model is now being used for both short-term and long-term forecasts. This paper describes several ongoing activities that will improve the accuracy and usefulness of the model and forecasts. These include efforts to streamline or minimize the sampling and analysis requirements of annual $A$. fundyense cyst surveys, efforts to quantitatively describe or characterize the severity of predicted outbreaks, and plans to obtain real-time data on Alexandrium cell abundance and toxicity that can be assimilated into the models. Together, these and other activities are moving us towards an operational forecasting system for Alexandrium blooms in the region.
\end{abstract}

\section{Introduction}

Technological advances have expanded our capabilities for research and monitoring of HABs, but the blooms will always be under sampled because of the large space and time scales over which they occur (McGillicuddy 2010). As a result, models are being used to help extrapolate and interpret these sparse observations (Franks 1997; McGillicuddy et al. 2011). These include conceptual models (e.g., Anderson et al. 2005), empirical models (e.g., Blauw et al. 2010; Raine et al. 2010), and complex numerical models (e.g., He et al. 2008).

Numerical models with varying levels of sophistication have been developed. Some are purely three-dimensional physical models capable of resolving hydrography, into which HAB cells are introduced as passive particles. This is the approach taken by Velo-Suarez et al. (2010) who used particle techniques to explain the disappearance of D. acuminata blooms in the Bay of Biscay, France. A similar approach is followed by a HAB forecasting system developed for K. brevis blooms in the Gulf of Mexico (Stumpf et al. 2009). These HAB forecasts are made twice weekly during K. brevis bloom events, using a combination of satellite derived image products, wind predictions, and a rule-based model derived from previous observations and research. Blooms are detected and defined using ocean color satellite images, and bloom transport is then predicted using transport modeling with passive particle transport. Stumpf et al. (2009) examined the direction of transport at 90\% accuracy but found insufficient data to properly evaluate the magnitude of transport. For a bloom that could be identified to within a few kilometers, Wynne et al. (2011) evaluated use of a hydrodynamic model to forecast bloom location first determined from satellite imagery. Both distance of movement and extent were consistently improved by adding the model. 
The next step in sophistication and complexity is to couple a detailed biological submodel to a hydrographic model. One example is a physical-biological model of Alexandrium bloom dynamics that has been developed for the Gulf of Maine region in the US (McGillicuddy et al. 2005; He et al. 2008). This model is based on a hydrographic submodel that can realistically simulate water motion over this large region, driven by winds, tides, stratification, river run off, and large-scale forcing from the open ocean. A second submodel is then coupled to the hydrography, simulating the germination of Alexandrium cysts from seed beds in the region (Anderson et al. 2005), and the subsequent growth of the population, regulated by temperature, salinity, sunlight and nutrients. The timing and rates of cyst germination and cell growth are parameterized from laboratory experiments on cultures of $A$. fundyense (Stock et al. 2005). A temperature-dependent mortality function incorporates a range of loss factors, including grazing and encystment. This model has demonstrated good skill at reproducing observations (Stock et al. 2005; He et al. 2008) and has been heavily used for hindcasts (looking at past events to understand underlying mechanisms; He et al. 2008; Li et al. 2009). It is also being used to issue weekly nowcasts and forecasts (looking forward 3 or 4 days) and even seasonal or annual forecasts (McGillicuddy et al. 2011).

Despite its sophistication, there are several aspects of this modeling and forecasting effort that need to be improved. These include: 1) the model's reliance on an annual cyst mapping survey which is expensive and time-consuming; 2) the difficulty in describing or characterizing bloom predictions in terms of severity of impacts; and 3) the need for real-time data on cell abundance that can be assimilated into the model to improve accuracy. This paper briefly discusses ongoing efforts to address these three important aspects of HAB forecasting.

\section{Cyst mapping.}

The Alexandrium population dynamics model is initiated from a quantitative map of A. fundyense cyst distribution and abundance obtained from a ship-based sediment mapping survey conducted during the fall of the years preceding the bloom simulation or forecast. An example of one of these cyst maps is shown in Figure 1, along with a map of the stations used to derive that map. The surveys require sediment coring at more than 100 stations, requiring 10 days or more of ship time for core collection alone. Once the cores are collected, several months of time are required for sediment

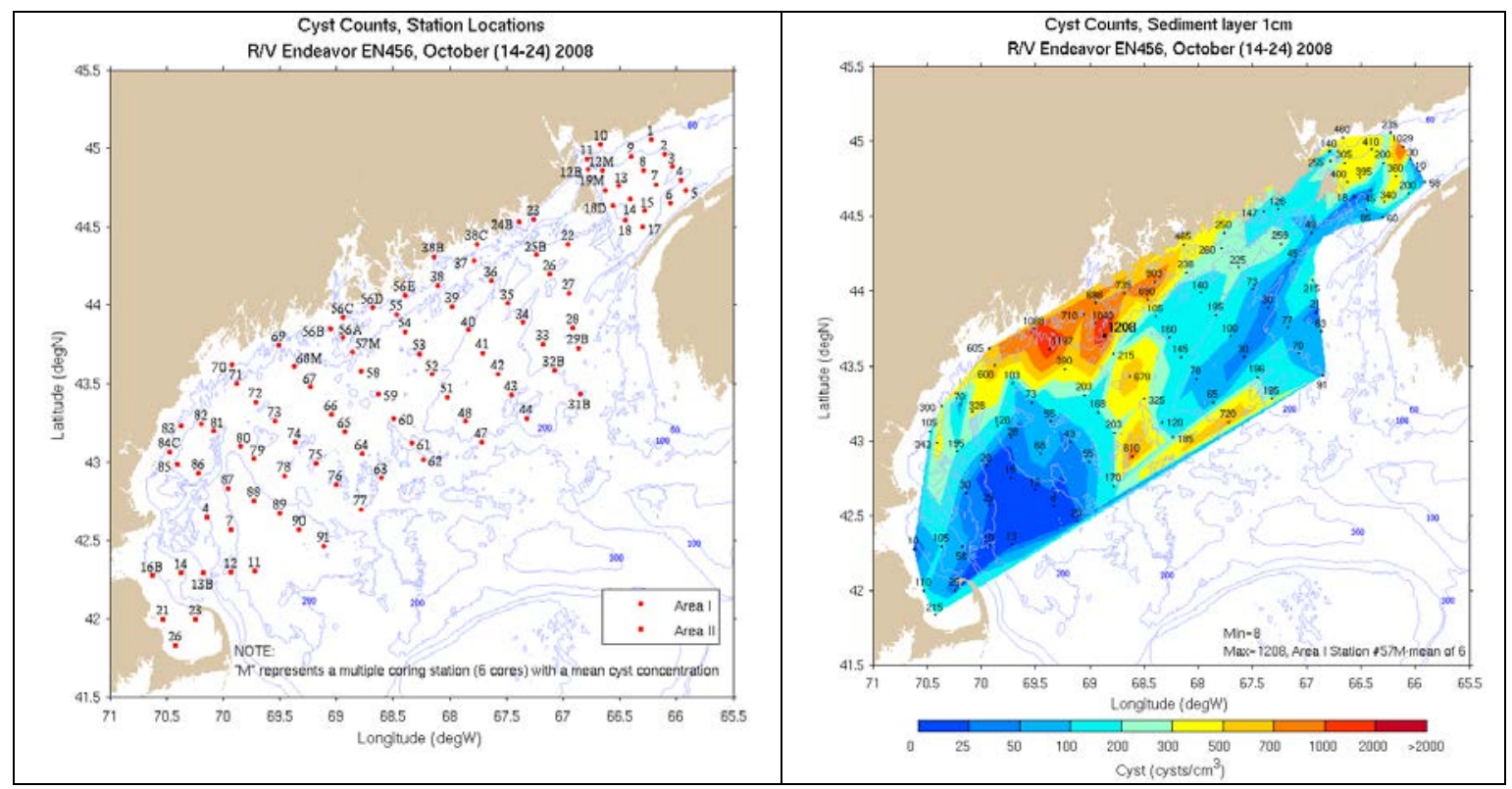

Figure 1. Cyst survey stations and example map. A) Station map for 2008 cyst survey; B) 2008 cyst abundance, 0-1 cm layer. 
processing and microscopic identification and enumeration of $A$. fundyense cysts.

The expense and time required for these cyst mapping surveys are significant, and need to be dramatically reduced if the Alexandrium model is to be used for operational forecasting of HABs in the region, as is planned. In order to accomplish this, a project was initiated based on an examination of existing survey data that suggested that the spatial distribution of A. fundyense cysts in the Gulf of Maine exhibits a large-scale pattern that does not change from year to year, even though the overall cyst abundance varies interannually. A time-series of cyst maps from 1997 to 2010 (Figure 2) documents the persistence of two major cyst deposits in the system: one in the Bay of Fundy and the other offshore of mid-coast Maine. Considerable interannual variability has been observed in the total abundance of $A$. fundyense cysts in the Gulf, spanning an order of magnitude or more over 9 years surveyed (Anderson et al. in prep). In a study that will be described elsewhere (Anderson et al. in prep.), cyst abundance data are being used to develop and test a statistical model of distributional patterns and characteristics. Once a satisfactory model has been fit to the data, it should be possible to optimize the cyst sampling design with a significantly reduced number of sampling locations. Our objective is to identify the most informative locations and transects, and to design a sampling program that would provide a realistic regional cyst map with a minimal expenditure for ship and personnel time. The sampling program would include periodic full cyst surveys to make sure the fundamental cyst distribution has not changed over time.

Progress to date has been very encouraging. A statistical model for cyst abundance has been developed based on the stations that are common to all of the eight surveys. The model appears to capture a large fraction of the observed interannual variability,
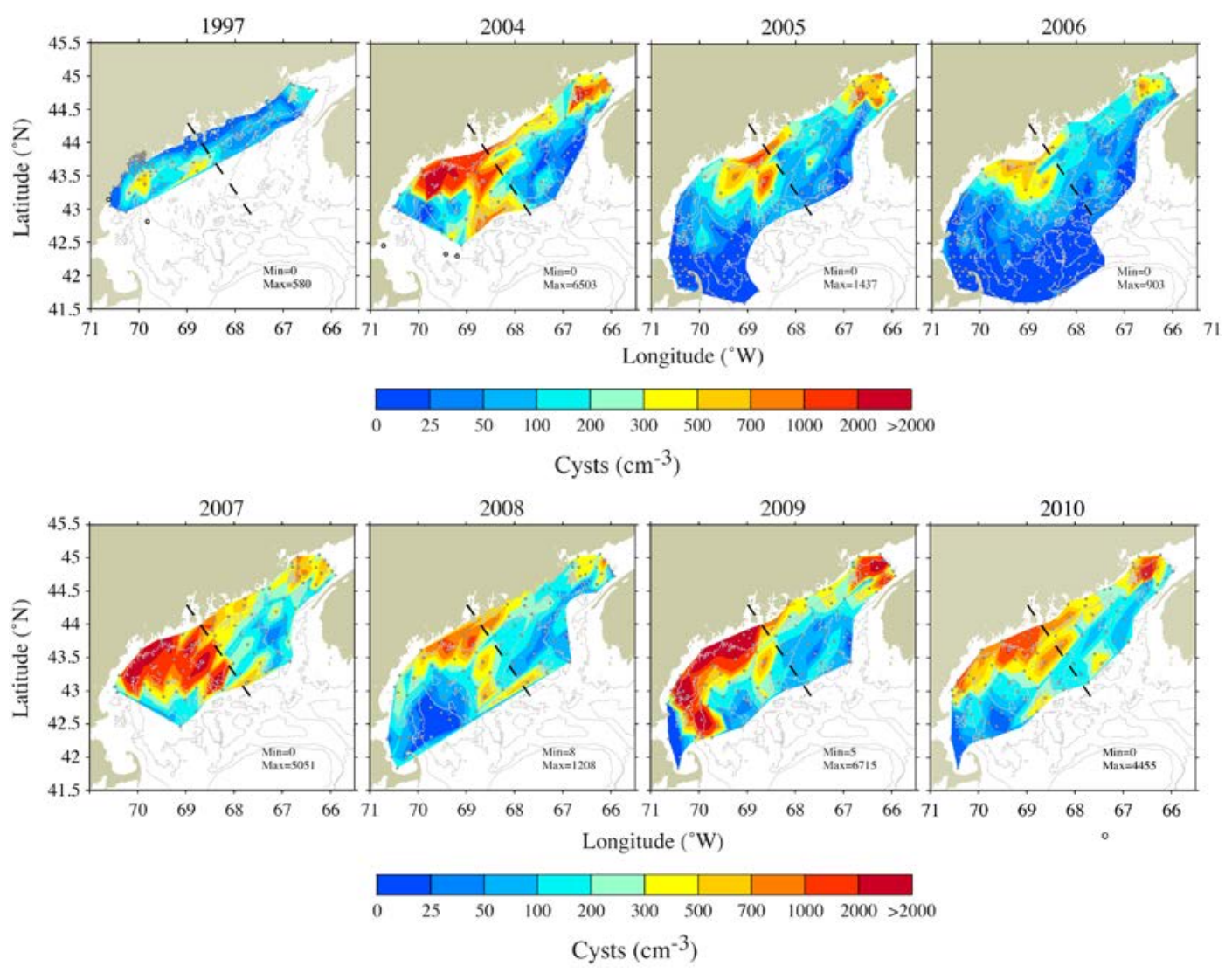

Figure 2. Cyst abundance in the Gulf of Maine, 1997 and 2004-2010. (From Anderson et al., in prep.) 
suggesting that there is a generic or common relative distribution of cysts. In other words, each station tends to have a consistent proportion of the total cysts being mapped that year, with only the total number of cysts varying. The spatial pattern or relative distribution of cysts is thus relatively constant, but the magnitude or overall abundance varies year to year. This makes sense oceanographically, as the currents and manner in which cysts will be formed in the plankton, deposited in the sediments, and then reworked and redeposited through time would be relatively similar between years in the large Gulf of Maine system, whereas the overall abundance of cysts produced would vary. In principle then, it should be possible to sample a relatively small number of stations, determine the departure from the generic or common cyst distribution pattern at each of those stations, and then use the average departure to scale all stations to obtain a full or extrapolated cyst map. These extrapolated maps can then be used by the Alexandrium population dynamics model to simulate the bloom for the next year.

We are currently evaluating the validity of this minimized sampling strategy approach using the time series of cyst maps that we already have (Figure 2), combined with comparative Alexandrium model runs that are based on the original versus the extrapolated map for each year. In this way, we can quantitatively assess the accuracy that is lost in the model simulations when a reduced sampling regime is used for the cyst mapping. It is hoped that the reduction in accuracy will be small, and acceptable given the significant cost and time savings that the reduced sampling strategy will bring.

\section{Bloom categorization}

For the seasonal forecasts that we have issued since 2008, it has been a challenge to describe the severity of the bloom that is being predicted. Our approach to the forecasting (described in McGillicuddy et al. 2011) generates estimates of regionwide Alexandrium cell abundance for the forthcoming bloom season, but does not yet project toxicity and shellfish closures along the coast. Press releases issued to describe the forecasts have used bloom descriptors that are relatively general (e.g., "severe", "moderate”, "moderately large") and that therefore do not provide the type of information that the general public and resource managers would like. We would like to provide information analogous to that given in severe storm forecasts such as those for hurricanes, which are designated Category 1-5 based on their projected wind speeds. Such information is of great value to those anticipating an outbreak, as the specifics of each category are known, and the extent of damage or the precautions necessary to avoid damage are clear.

After discussions with officials responsible for shellfish monitoring along the New England coast, we determined that the parameter that would be most useful in a forecast would be the extent of coastline that is closed due to PSP toxins. For the forecast, information on estimated closure extent would be issued prior to the bloom season each year - in late winter or early spring, once cyst abundance from the previous fall has been determined and the forecast model run. State monitoring programs and the fisheries industry could manage resources accordingly. For example, if the potential for a significant bloom is forecast, managers could ensure that sufficient staff are retained to conduct extended sampling as needed. As the bloom season progresses, updates to the forecasts can be issued based on available cruise sampling, shellfish toxicity results, and autonomous bloom monitoring, as described below. We therefore initiated a program to develop a set of classification 
categories that could be used to describe the severity of Alexandrium blooms within the region. This effort is described in detail in Kleindinst et al. (in prep), and is summarized as follows.

Historical data on shellfish closures were used to produce maps in which the areas that were closed to harvesting were indicated using a consistent set of straight-line segments. Examples of two years with widely differing levels of shellfish closures are shown in Figure 3. Digital mapping tools were used to measure the length of coastline closed each year from 1977 to the present. These distances were then clustered into 3 categories (0-199 km, $200-399$, and $400-600 \mathrm{~km})$. These categories are tentatively termed "Limited", "Moderate", and "Extensive". These terms were selected because they have a geographic connotation, whereas other terms such as "severe" do not. When future forecasts are issued, these terms will be used, and the implied length of coastline closures will be provided as well. To our knowledge, this is the first effort to quantify or classify the severity of HAB outbreaks.
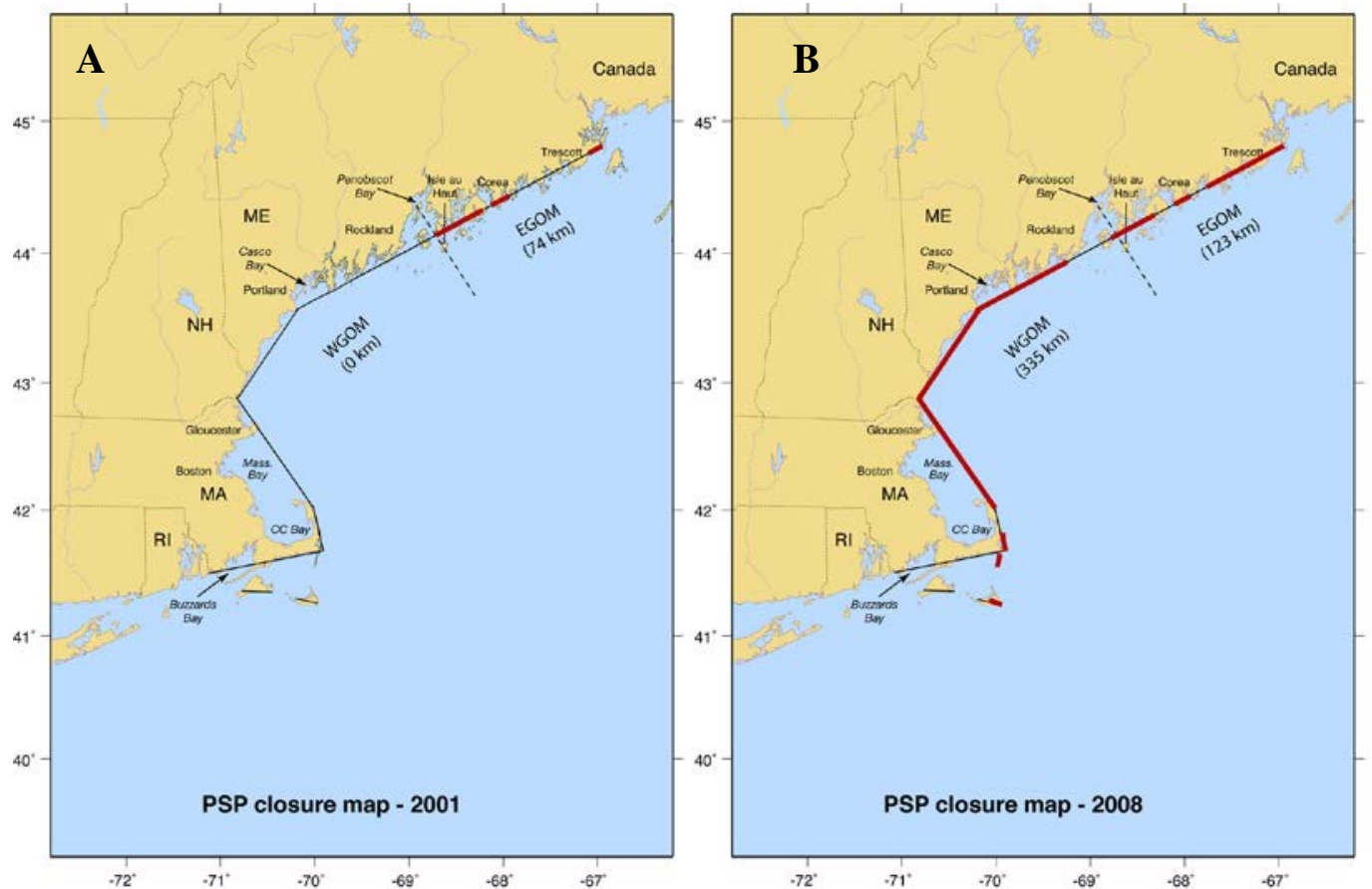

Figure 3. Example maps of varying closure levels due to PSP in the Gulf of Maine - A) 2001; B) 2008. With the new bloom severity classifiers, 2001 would be termed "Limited", and 2008 "Extensive".

\section{Real-time data on Alexandrium cell abundance and toxicity}

One of the reasons that weather forecasts are so accurate is that data from meteorological stations are constantly being assimilated into the numerical models that are used for those forecasts, with those models then being rerun to provide more accurate simulations that reflect current observations. This is what is needed for HAB forecasts, but will require high-frequency environmental and biological observations. The former are becoming available through the expanding ocean observing system using moored instruments capable of measuring temperature, salinity, currents, and other hydrographic parameters. Unfortunately, sensors that can obtain real-time data on organisms such as Alexandrium are at a much earlier stage of development, yet these are critical to the success of HAB forecasting. Major developments in this 
regard are instruments that can robotically sample water and detect HAB cells and their toxins. One instrument that provides these capabilities and that can be configured for use in ocean observing systems is the Environmental Sampling Processor (ESP; Goffredi et al. 2006; Scholin et al. 2009). The ESP autonomously collects water samples, concentrates microorganisms (particulates), and automates application of molecular probes to identify specific microorganisms and their gene products. The instrument can be bundled with other sensors such as a CTD, fluorometer, transmissometer, and nutrient analyzer. Data from the sensors along with results of the probe assays are uploaded periodically from the instrument to a shore station for analysis. Two-way communication allows for rescheduling of mission sampling profiles if desired. The ESP is now commercially available, and instruments will soon be deployed to augment HAB research and management programs.

For our Gulf of Maine Alexandrium program, a vision for the future would be that of arrays of moored ESPs capable of detecting HAB cells and their toxins (Figure 4). This configuration reflects the desire of state shellfish managers for early warning bloom detection near major shellfish resources along the coast and does reflect the geographic and hydrographic nature of the regional bloom phenomenon (i.e., bloom

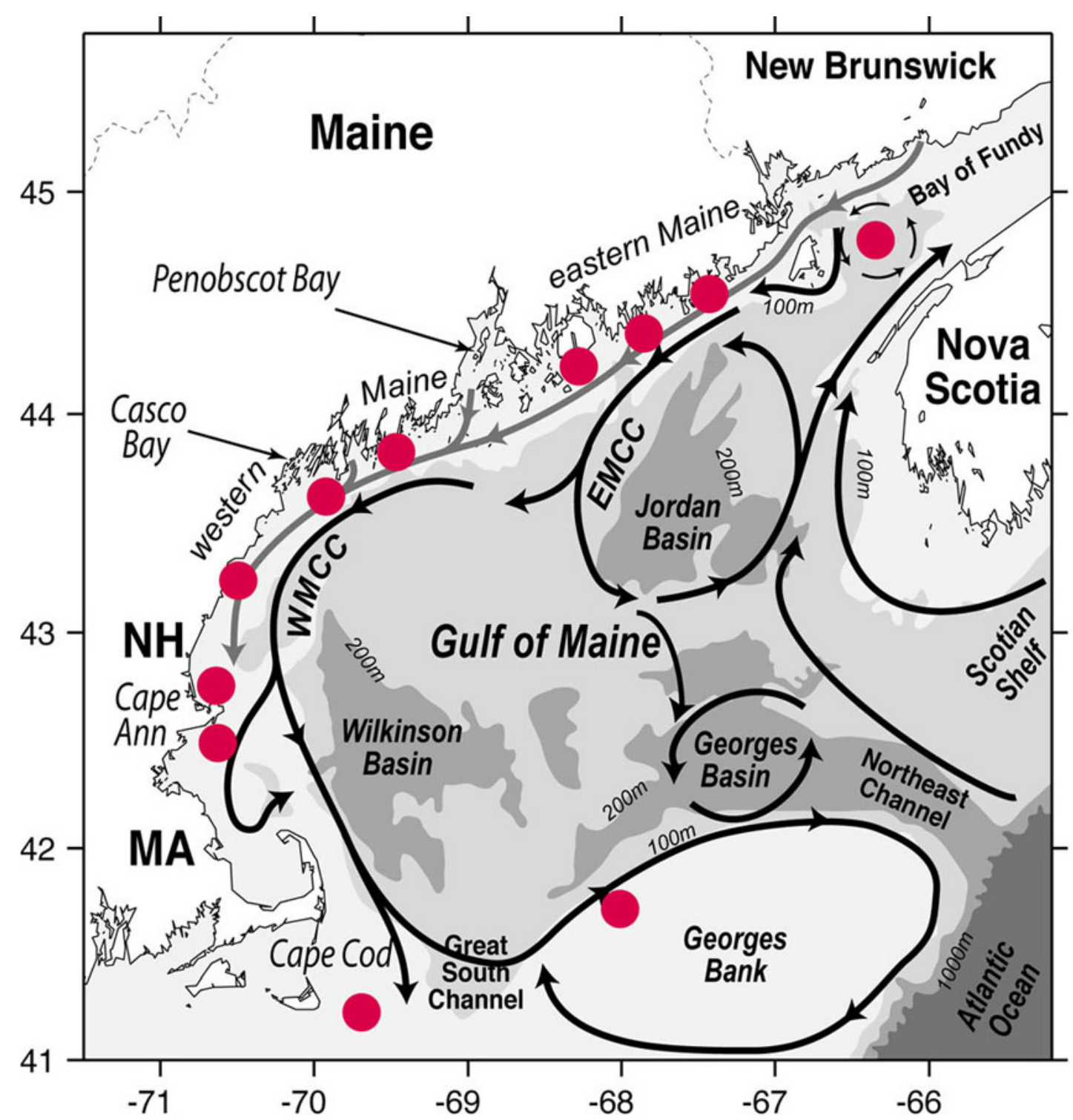

Figure 4. Desired locations for an ESP array in the Gulf of Maine. These sites were selected in collaboration with shellfish managers who desire early warning at key locations. 
initiation in the Bay of Fundy and other cyst seedbed areas, and transport from east to west in the Maine coastal current system; Anderson et al. (2005)). Other configurations are possible that would place instruments further from shore, thereby providing information on the gulf-wide bloom distribution. In either case, Alexandrium cell abundance and toxicity data would be transmitted to shore and assimilated into our numerical model to improve accuracy and contribute to decisions on harvesting closures or other strategies to mitigate HAB impacts. In this regard, HAB sensors are viewed by many as an important component of the emerging ocean observing system infrastructure worldwide.

\section{Summary}

A long-standing goal of HAB research has been the development of forecasting capabilities that can accurately simulate the development and impact of blooms ofHAB species in specific regions. In the Gulf of Maine, a sustained research program has led to the formulation and application of a population dynamics model for $A$. fundyense that is currently being used for both short-term and long-term forecasts. In both cases, the accuracy of the forecasts is limited by the lack of real-time data on Alexandrium abundance and toxicity. Other constraints include the reliance of the model on expensive and time-consuming cyst mapping surveys, and the difficulty in describing the severity of the predicted blooms. Efforts are underway to address each of these issues, and our hope is that in the relatively near future, forecast accuracy and utility will be greatly enhanced through these endeavors.

\section{Acknowledgements}

Research support provided through the Woods Hole Center for Oceans and Human Health, National Science Foundation (NSF) Grants OCE-0430724, and OCE0911031; and National Institute of Environmental Health Sciences (NIEHS) Grant 1P50-ES012742-01, the ECOHAB Grant program through NOAA Grants NA06NOS4780245 and NA09NOS4780193, and the MERHAB Grant program through NOAA Grant NA11NOS4780025. This is ECOHAB contribution \# 687.

\section{References}

Anderson, D.M., Stock, C.A., Keafer, B.A., Bronzino Nelson, A., Thompson, B., et al., 2005. Alexandrium fundyense cyst dynamics in the Gulf of Maine. Deep-Sea Research Part II 52(1921), 2522-2542.

Blauw, A.N., Los, F.J., Huisman, J., Peperzak, L., 2010. Nuisance foam events and Phaeocystis globosa blooms in Dutch coastal waters analyzed with fuzzy logic. Journal of Marine Systems 83, 115-126.

Franks, P.J.S., 1997. Coupled physical-biological models for the study of harmful algal blooms. Ocean Research 19, 153-160.

Goffredi, S.K., Jones, W., Scholin, C., Marin, R., Hallam, S., Vrjenhoek, R.C., 2006. Molecular detection of marine larvae. Marine Biotechnology 8, 149-160.

He, R., McGillicuddy, D.J., Keafer, B.A., Anderson, D.M., 2008. Historic 2005 toxic bloom of Alexandrium fundyense in the western Gulf of Maine: 2. Coupled Biophysical Numerical Modeling. Journal of Geophysical Research-Oceans 113, C07040, doi:10.1029/2007JC004602.

Li, Y., He, R., McGillicuddy, Jr. D.J., Anderson, D.M., Keafer, B.A, 2009. Investigation of the 2006 Alexandrium fundyense bloom in the Gulf of Maine: In situ observations and numerical modeling. Continental Shelf Research 29(17), 2069-2082.

McGillicuddy, Jr., D.J., Anderson, D.M., Lynch, D.R., Townsend, D.W, 2005. Mechanisms regulating large-scale seasonal fluctuations in Alexandrium fundyense populations in the Gulf of Maine: Results from a physical-biological model. Deep-Sea Research Part II 52(19-21), 2698-2714. 
McGillicuddy, Jr., D.J., 2010. Models of harmful algal blooms: Conceptual, empirical, and numerical approaches. In D. McGillicuddy (Ed.), GEOHAB Modeling, Journal of Marine Systems 83(3-4), pp. 105-107.

McGillicuddy, Jr., D.J., Townsend, D.W., He, R., Keafer, B.A., Kleindinst, J.L., et al., 2011. Suppression of the 2010 Alexandrium fundyense bloom by changes in physical, biological, and chemical properties of the Gulf of Maine. Limnology and Oceanography 56(6), 2411-2426.

Raine, R., McDermott, G., Silke, J., Lyons, K., Nolan, G., Cusack, C., 2010. A simple short range model for the prediction of harmful algal events in the bays of southwestern Ireland. Journal of Marine Systems 83(3-4), 150-157.

Scholin, C., Doucette, G., Jensen, S., Roman, B., Pargett, D., et al., 2009. Remote detection of marine microbes, small invertebrates, harmful algae and biotoxins using the Environmental Sample Processor (ESP). Oceanography 22, 158-167.

Stock, C.A., McGillicuddy, D.J., Solow, A.R., Anderson, D.M., 2005. Evaluating hypotheses for the initiation and development of Alexandrium fundyense blooms in the western Gulf of Maine using a coupled physical-biological model. Deep-Sea Research Part II 52(19-21), 2715-2744.

Stumpf, R.P., Tomlinson, M.C., Calkins, J.A., Kirkpatrick, B., Fisher, K., Nierenberg, K., Currier, R., Wynne, T.T., 2009. Skill assessment for an operational algal bloom forecast system. Journal of Marine Systems 76, 151-61, ISSN 0924-7963, DOI: 10.1016/j.jmarsys.2008.05.016

Velo-Suárez, L., Reguera, B., Gonzáles-Gil, S., Lunven, M., Lazure, P., Nézan, E., Gentien, P. 2010. Application of a 3D Lagrangian model to explain the decline of a Dinophysis acuminata bloom in the Bay of Biscay. Journal of Marine Systems 83(3-4), 242-252.

Wynne, T.T., R.P. Stumpf, M.C. Tomlinson, D.J. Schwab, G.Y. Wtabayashi, and J.D. Christensen. 2011. Estimating cyanobacterial bloom transport by coupling remotely sensed imagery and a hydrodynamic model. Ecological Applications, 21(7): 2709-2721. 